\title{
ON THE EDGE
}

\section{Quick decisions for a difficult future.}

\section{BY MONYA BAKER}

S ally tried to remember what her mouth had tasted like the last time she'd been able to brush her teeth. She imagined herself in her old bathroom, water pouring luxuriously from tap straight to drain, water that would start to flow clean and cold with an oblivious flick of the wrist and keep flowing while she scoured her teeth with mint paste. Concentrating on those tastes could only keep her from feeling thirsty for so long.

The land was flat and the dirt was red, dry and crumbly. Its dust tracked the creases in her face and hands; she thought she must look like she'd been made up to seem even older than she was. Certainly her grandsons walking silently beside her seemed like very old children. At the first sign of shade, she decided, they would take shelter.

"Nana?" Jacob tugged her wrist and pointed into the haze on the horizon.

"What do you see, child?" Even when they'd still had clothes that were clean, the grime on Sally's glasses would build up faster than she could wipe it away.

"Something moving."

"How many somethings? How big?" They'd gone too far to dart back to a hiding place. And anyway, running could be taken to mean that they had something worth stealing. They did - a few days' worth of water and food. They'd been in worse situations before.

Soon enough, she saw it too. A wide black rubber base carrying a metallic blue pillar topped by a broad white solar panel, like some engineer's crazy idea of an Easter bonnet. A class D model, a rare sight these days; most hadn't lasted long after the Collapse. Class Ds were originally programmed for light construction and assembly jobs. Surveillance would be deprioritized. It should be easy enough to trick.

The big machine paused. Its metal column pivoted, revealing a black panel of sensors. "Pedestrians. Halt. State reason for presence."

The clarity of the words surprised Sally. By now, dust usually caked speakers on drones, muffling their machine voices.

"Family unit. Leaving area."

Class Ds functioned better with set phrases. The irony was that Sally wasn't lying. Still, she held both hands over her chest, hoping the sensors wouldn't pick up on her quickened heartbeat.

"Pedestrian, are you in need?"

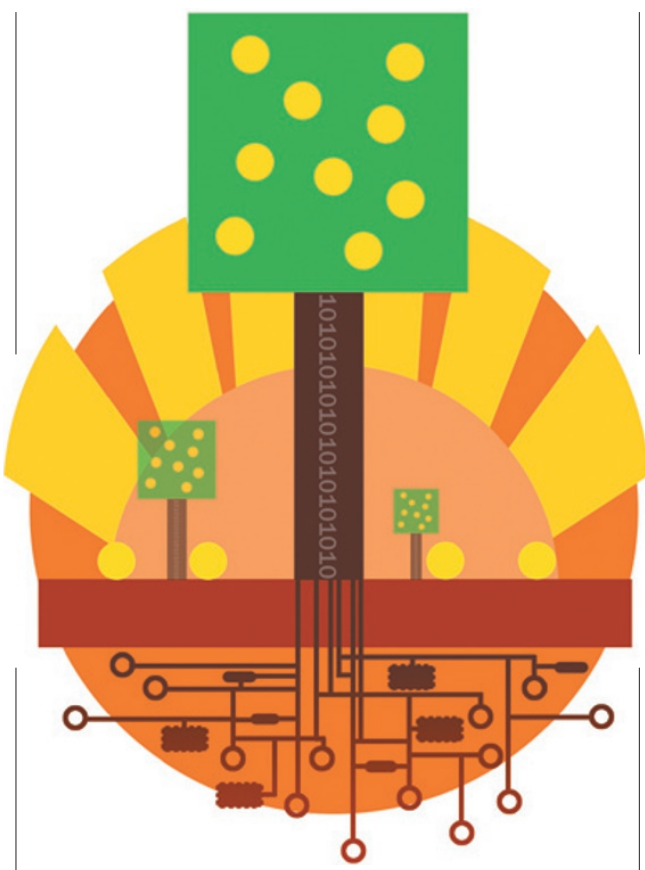

Sally hadn't heard this question from a Class D before. Her thoughts raced. She'd been an engineer once, but robotics had evolved beyond human science. It was no longer possible to isolate variables and optimize. Emergent properties were inevitable. And some of those properties had a mind of their own.

"Pedestrian," the drone repeated, "are you in need?"

She tried to say 'negative', but the dust caught in her throat and she coughed instead.

"We could use more water," said Jacob.

The drone moved closer, humming. A panel on the blue pillar opened to reveal a screen displaying a satellite map. A yellow arrow showed their location on a large plateau. A kilometre to the west the land descended sharply, then levelled into a field of trees planted in straight rows, startlingly green, surely an orchard.

"Family unit, you will be accompanied to the settlement."

The drone shifted its solar panel, creating an overhang of shade. Jacob rushed into the shadow and Colin fell into place beside him. They were too young to remember life in hiding, learning different models' blindspots,

$\rightarrow$ NATURE.COM

Follow Futures on Facebook at: go.nature.com/mtoodm seeing deadly results of poor estimates. One Class D couldn't catch three people, Sally knew, but the boys couldn't survive on their own. She moved between the thing and her grandchildren.

Her proximity must have triggered a sensor. She heard a click, and then a voice. A recorded voice: young, male, human.

"Greetings and congratulations," the anonymous man said. "You have recognized this machine for what it is: a tool, a servant. When you join us, you will see that the Collapse has reversed. Society is rising, with technology we can trust. This machine is our best example."

The drone began to move. Sally and her grandsons had to stay close to keep in the shade, but Jacob and Colin did not take her hands again. They rested their drawstring bags on the drone's broad base. Sally picked the bags up and handed them back.

Sooner than she expected, they reached the edge of the plateau. From this angle Sally could just see gold coins of fruit in the trees. A pair of rusted ladders, lashed end to end, led the way down. Beside it was a well-kept platform attached to an assembly of cables and pulleys, a jury-rigged freight elevator. Below, Sally saw half a dozen huts surrounding what must be a well. Pipes extended from the well into each hut. Running water had been reinvented.

Their presence must have activated a second transponder. Sally heard another click, and the human voice spoke again. "Welcome to a new beginning," it said. "You will see what our civilization can do." The drone began rolling towards its elevator, ready to begin its descent. The boys followed the machine. They paused at the ladders and turned to her.

Two words came clear and hard into Sally's head. Not again.

She waited until the drone's black rubber base was halfway on the platform. Then she rushed to the cluster of pulleys and put all her weight on an interior cable. It popped off with enough force to throw her to the ground. She heard the drone crash against the cliff and then down to its base.

Sally didn't pause to look at the wreck below or the skin that had been scraped off her knuckles. She put her hands on her grandsons' shoulders and turned them as a unit to the east, the centre of the plateau.

"Let's go," she said.

Monya Baker works for Nature and Nature Methods, where she writes about emerging technologies that help biomedical researchers to answer new kinds of questions. 